\title{
Is metabolic syndrome a discrete entity in the general population? Evidence from the Caerphilly and Speedwell population studies
}

\author{
J W G Yarnell, C C Patterson, D Bainton, P M Sweetnam
}

\begin{abstract}
Objective-To examine the clinical and epidemiological utility of the concepts of metabolic syndrome and insulin resistance syndrome in two prospective cohort studies of white men.

Methods-Men aged 45-63 years were screened for evidence of ischaemic heart disease (IHD) between 1979 and 1982 and followed up at regular intervals thereafter. Non-fatal coronary events were validated from hospital records and fatal coronary events from death certificates.

Results-Analysis of serum insulin concentrations in non-diabetic individuals measured at entry to the study showed no independent contribution to the prediction of subsequent IHD at 10 year follow up. Blood glucose concentrations, however, showed a small independent contribution in the combined cohort in the upper fifth of the distribution. Three different models of metabolic syndrome among non-diabetic individuals were defined based on tertiles, medians, and clusters. The predictive value of each model was assessed using logistic regression before and after adjustment for conventional and metabolic risk factors. After adjustment the odds were non-significant and close to unity.

Conclusions-This study did not detect any complex relation among the five variables defining metabolic syndrome; the excess risk seems to be no greater than can be explained by individual effects of the defining variables in a multiple logistic model.

(Heart 1998;79:248-252)
\end{abstract}

Keywords: metabolic syndrome; insulin resistance; screening; ischaemic heart disease; epidemiology

Hyperinsulinaemia, insulin resistance, and cardiovascular risk factors, such as dyslipidaemia, hypertension, and obesity, ${ }^{12}$ are closely linked with non-insulin dependent diabetes mellitus. ${ }^{3-8}$ Reaven $^{9}$ has suggested that insulin resistance labelled as metabolic syndrome may occur in up to $25 \%$ of the normal population. We examined evidence for the existence of this syndrome in two general population based cohorts of British men. Previous studies of insulin $^{10}$ (Caerphilly cohort) and glucose ${ }^{11}$ (Caerphilly and Speedwell cohorts) were based on five year follow up of these populations.
These analyses have been combined and extended in a 10 year follow up.

\section{Methods}

STUDY POPULATIONS

Men were selected from a defined area in Caerphilly. They were aged between 45 and 59 years when first examined. A total of 2512 $(89 \%)$ of 2818 men eligible for study were seen. In Speedwell men were selected from the age sex registers of 16 general practitioners working from two neighbouring health centres. The men were between 45 and 59 years of age when chosen, immediately before the study started. They were aged between 45 and 63 years when first examined. A total of 2348 (92\%) of 2552 men eligible for study were seen. The total number of men for the combined cohort was 4860 .

SURVEY METHODS AND FOLLOW UP

The two studies had a common core protocol and procedures, which have been described elsewhere. ${ }^{10-12}$ Briefly, at recruitment, the men attended an afternoon or evening clinic at which they completed a standard medical and smoking history, and the London School of Hygiene and Tropical Medicine chest pain questionnaire. Height, weight, and blood pressure were also measured and a 12 lead electrocardiogram (ECG) recorded. The men were asked whether they had ever been diagnosed as having diabetes. They returned, after an overnight fast, to an early morning clinic where a blood sample was taken with minimal venous stasis. Fasting samples were obtained from 4641 men. The results reported refer to the second follow up in Caerphilly. This was at a nearly constant interval of mean (SD) 120 (6) months. The results in Speedwell relate to the third follow up and the mean (SD) interval was 112 (3) months. The chest pain questionnaire was administered at follow up and a second ECG recorded. The questionnaire was extended to include questions about hospitalisation for severe chest pain. These, together with hospital activity analysis notifications of admissions coded as 410-414-ischaemic heart disease (IHD) in the International classification of diseases, (9th revision) (ICD-9) - were used as the basis for a search of hospital notes for events that satisfied the World Health Organisation (WHO) criteria for definite acute myocardial infarction. A copy of the death certificate of men who died before the end of follow up was automatically received from the National Health Service Central Register. This
Accepted for publication 12 November 1997 
Table 1 Partial correlation coefficients (adjusted for age) between selected variables in non-diabetic subjects from Caerphilly and Speedwell $(n=4197)$

\begin{tabular}{lllll}
\hline & Log triglyceride & Body mass index & Glucose & $\begin{array}{l}\text { Diastolic blood } \\
\text { pressure }\end{array}$ \\
\hline Log insulin & $0.44 /-$ & $0.39 /-$ & $0.32 /-$ & $0.17 /-$ \\
Log triglyceride & & $0.27 / 0.25$ & $0.14 / 0.11$ & $0.16 / 0.11$ \\
Body mass index & & & $0.23 / 0.22$ & $0.28 / 0.25$ \\
Glucose & & & $0.09 / 0.14$ \\
\hline
\end{tabular}

information enabled three categories of incident IHD events to be defined: IHD death (cause of death coded as 410-414 in the ICD9); clinical non-fatal myocardial infarction (an event satisfying WHO criteria); and electrocardiographic myocardial infarction (major or moderate Q/QS waves, Minnesota codes 1-1-1 to $1-2-5$ or 1-2-7 on any follow up ECG when there were no Q/QS waves, Minnesota codes 1-1-any, 1-2-any, or 1-3-any on the recruitment ECG). ECGs were read by experienced observers. The same observers read, independently, baseline and follow up ECGs for both studies. A major IHD event was defined as one or more of the three possible outcomes described.

\section{LABORATORY METHODS}

Blood samples were taken with minimum haemostasis after an overnight fast. Methods for the determination of fasting insulin, glucose, and lipid variables have been reported elsewhere. ${ }^{10}{ }^{11}$ Insulin was measured only in samples from the Caerphilly cohort. ${ }^{10}$

STATISTICAL METHODS

Assessment of the nature of the interrelations among the variables used to define metabolic syndrome was performed using log linear models for multidimensional contingency tables. ${ }^{13}$ In these models the results on each of the variables for any man were simply considered as being above or below a cut off. An analysis involving $\mathrm{n}$ variables therefore gives rise to a contingency table with 2 n cells. The number of men assessed as having the syndrome - that is, values of each variable above the cut off, is given by the entry in one cell of the contingency table and may be compared to the number predicted by models specifying various patterns of association among the variables. A $\chi^{2}$ statistic provides a test of the goodness of fit of a model to the actual pattern of association observed among the variables across the whole contingency table. Cluster analysis was performed using a

Table 2 Summary of log linear models fitted to metabolic variables to predict the number of men with metabolic syndrome

\begin{tabular}{|c|c|c|c|c|}
\hline & \multicolumn{2}{|c|}{$\begin{array}{l}\text { Four variable model } \\
\text { (combined cohort) }\end{array}$} & \multicolumn{2}{|c|}{$\begin{array}{l}\text { Five variable model } \\
\text { (Caerphilly cohort) }\end{array}$} \\
\hline & Tertiles & Medians & Tertiles & Medians \\
\hline Total men & 4197 & 4197 & 1896 & 1896 \\
\hline $\begin{array}{l}\text { Actual number of men with } \\
\text { metabolic syndrome according to } \\
\text { definition }\end{array}$ & 154 & 463 & 50 & 167 \\
\hline $\begin{array}{l}\text { Number of men with metabolic } \\
\text { syndrome predicted by pairwise } \\
\text { association model }\end{array}$ & 154.4 & 466.9 & 55.8 & 177.7 \\
\hline $\begin{array}{l}\text { Lack of fit test for pairwise } \\
\text { association model } \chi^{2} \text { statistic } \\
\mathrm{df} \\
\mathrm{p} \text { value }\end{array}$ & $\begin{array}{l}3.7 \\
5 \\
0.60\end{array}$ & $\begin{array}{l}9.3 \\
5 \\
0.10\end{array}$ & $\begin{array}{l}18.2 \\
16 \\
0.31\end{array}$ & $\begin{array}{l}22.3 \\
16 \\
0.13\end{array}$ \\
\hline
\end{tabular}

non-hierarchical $\mathrm{K}$ means algorithm. This method clusters men into a prespecified number, $\mathrm{K}$, of groups the composition of which is not initially known. After specifying a suitable centre for each cluster, each man is assigned to the cluster in which the centre is closest. When all men have been assigned, the cluster centres are recalculated. The assignment then takes place again, typically resulting in some men being reassigned to a different cluster. This process is repeated until there is convergence. Here, the number of groups was preset at two $(\mathrm{K}=2)$, and closeness to a cluster centre was defined using Euclidean distance calculated with the variables standardised to zero mean and unit variance. Insulin and total triglyceride concentrations were log transformed before standardising. In anticipation of two clusters of unequal size, the initial cluster centres were placed at values of 0.00 and 1.645 for each of the standardised variables, corresponding roughly to the 50th and the 95th centiles of the distributions. Analysis of events during follow up was performed using multiple logistic regression with the occurrence, or not, of a major IHD event as the principal outcome variable. Men with evidence of IHD when first examined were not excluded from the analyses but their increased risk was allowed for by including pre-existing IHD as a factor in the regression model. In this instance a broad epidemiological definition of pre-existing IHD was used: men with severe chest pain and/or angina on the chest pain questionnaire and/or probable or possible ECG ischaemia according to Whitehall criteria. ${ }^{14}$ Death from any cause was also analysed as a separate outcome variable. Any difference in incidence between the two study areas - for example, arising from their slightly different lengths of follow up, was allowed for by including area as a two level factor in the logistic model. The assumption that IHD risks associated with independent variables in the two areas were parallel on the logit scale was tested by including interactions with area in the model. None was statistically significant. No time to event was available for incidence cases of IHD defined by significant changes in the Minnesota ECG codes. Time to event analyses were not performed for this reason and because the average length of follow up was nearly constant within each area.

DIABETIC MEN

Ninety four men said that diabetes was diagnosed by their general practitioner or a consultant physician before our baseline examination. An additional 53 individuals had fasting glucose concentrations of $7.8 \mathrm{mmol} / 1$, which is the threshold value presently used by the $\mathrm{WHO}^{15}$ to define diabetes. Diabetic men as defined earlier were excluded from further analyses.

\section{Results}

Analyses are based on 4197 of 4462 nondiabetic men in the combined cohort who had a complete set of data relevant to risk of IHD, with the possible exception of insulin. A total of 527 of 4197 men died and there were 492 
Table 3 Relative odds of incident ischaemic heart disease by fifths of insulin distribution in non-diabetic men in the Caerphilly cohort $(n=1896)$

\begin{tabular}{|c|c|c|c|c|}
\hline \multirow[b]{2}{*}{ Insulin range $(m U / l)$} & \multirow{2}{*}{$\begin{array}{l}\text { Men } \\
(n)\end{array}$} & \multirow{2}{*}{$\begin{array}{l}\text { Events } \\
(n)\end{array}$} & \multicolumn{2}{|l|}{ Relative odds } \\
\hline & & & Age adjusted only $(95 \% C I)$ & Multivariate ${ }^{\star}$ \\
\hline$\leqslant 3.0$ & 403 & 32 & 1.00 & 1.00 \\
\hline $3.1-4.6$ & 368 & 39 & $1.45(0.88,2.37)$ & $1.34(0.81,2.23)$ \\
\hline $4.7-6.5$ & 369 & 45 & $1.68(1.04,2.71)$ & $1.49(0.90,2.45)$ \\
\hline $6.6-10.0$ & 390 & 53 & $1.95(1.22,3.11)$ & $1.47(0.90,2.42)$ \\
\hline $10.1-$ & 366 & 52 & $2.05(1.28,3.27)$ & $1.27(0.75,2.17)$ \\
\hline Total & 1896 & 221 & & \\
\hline Heterogeneity test & & & $\begin{array}{l}\chi^{2}=11.9 \\
4 \mathrm{df}, \mathrm{p}=0.01\end{array}$ & $\begin{array}{l}\chi^{2}=3.29 \\
4 \mathrm{df}, \mathrm{p}=0.51\end{array}$ \\
\hline Trend test & & & $\begin{array}{l}\chi^{2}=10.8 \\
1 \mathrm{df}, \mathrm{p}=0.001\end{array}$ & $\begin{array}{l}\chi^{2}=0.79 \\
1 \mathrm{df}, \mathrm{p}=0.37\end{array}$ \\
\hline
\end{tabular}

^Included in multivariate model are: age, pre-existing IHD, smoking habit, diastolic blood pressure, total and HDL cholesterol, log triglyceride, and glucose.

incident IHD events. In the Caerphilly cohort there were 1896 non-diabetic men with insulin results among whom there were 223 deaths and 221 incident IHD events. Metabolic syndrome has been defined using different variables but we constructed two versions to simplify subsequent analyses: one included five variables - namely, insulin, glucose, triglyceride, body mass index, and diastolic blood pressure; and the other excluded insulin, which was not measured in the Speedwell cohort. Table 1 shows association among the variables in the non-diabetic population. The correlation coefficients given separately for the two cohorts are very similar.

Three empirical definitions of metabolic syndrome were made. Tertiles: men had to be in the top third of the distribution of each of the variables. There were 154 men $(3.7 \%)$ $(\mathrm{n}=4197)$ with four metabolic variables and $50(2.6 \%)(\mathrm{n}=1896)$ with five. Medians: men

Table 4 Relative odds of incident ischaemic heart disease by fifths of glucose distribution in non-diabetic men in combined cohort (Caerphilly and Speedwell)

\begin{tabular}{|c|c|c|c|c|}
\hline \multirow[b]{2}{*}{$\begin{array}{l}\text { Glucose range } \\
\quad(\mathrm{mmol} / \mathrm{l})\end{array}$} & \multirow[b]{2}{*}{$\operatorname{Men}(n)$} & \multirow[b]{2}{*}{ Events (n) } & \multicolumn{2}{|l|}{ Relative odds } \\
\hline & & & $\begin{array}{l}\text { Age adjusted only } \\
\text { (95\% CI) }\end{array}$ & Multivariate ${ }^{\star}$ \\
\hline$\leqslant 4.4$ & 827 & 85 & 1.00 & 1.00 \\
\hline $4.5-4.7$ & 948 & 101 & $1.02(0.75,1.38)$ & $0.95(0.69,1.31)$ \\
\hline $4.8-4.9$ & 775 & 75 & $0.91(0.65,1.26)$ & $0.81(0.58,1.14)$ \\
\hline $5.0-5.2$ & 882 & 103 & $1.11(0.82,1.51)$ & $1.01(0.73,1.38)$ \\
\hline $5.3-7.7$ & 765 & 128 & $1.65(1.23,2.22)$ & $1.39(1.02,1.90)$ \\
\hline Total & 4197 & 492 & & \\
\hline Heterogeneity test & & & $\begin{array}{l}\chi^{2}=19.6 \\
4 \mathrm{df}, \mathrm{p}=0.0006\end{array}$ & $\begin{array}{l}\chi^{2}=12.6 \\
4 \mathrm{df}, \mathrm{p}=0.01\end{array}$ \\
\hline Trend test & & & $\begin{array}{l}\chi^{2}=12.1 \\
1 \mathrm{df}, \mathrm{p}=0.0005\end{array}$ & $\begin{array}{l}\chi^{2}=4.87 \\
1 \mathrm{df}, \mathrm{p}=0.03\end{array}$ \\
\hline
\end{tabular}

*Included in the multivariate model are: age, pre-existing IHD, smoking habit, diastolic blood pressure, total and HDL cholesterol, log triglyceride, and area factor (Caerphilly $v$ Speedwell).

Table 5 Relative odds of incident ischaemic heart disease by four graded cut off points of glucose in non-diabetic men in combined cohort (Caerphilly and Speedwell)

\begin{tabular}{|c|c|c|c|c|}
\hline \multirow[b]{2}{*}{$\begin{array}{l}\text { Glucose range } \\
\quad(\mathrm{mmol} / \mathrm{l})\end{array}$} & \multirow[b]{2}{*}{ Men (n) } & \multirow[b]{2}{*}{ Events (n) } & \multicolumn{2}{|l|}{ Relative odds } \\
\hline & & & $\begin{array}{l}\text { Age adjusted only } \\
(95 \% \mathrm{CI})\end{array}$ & Multivariate ${ }^{\star}$ \\
\hline$\leqslant 4.7$ & 1775 & 186 & 1.00 & 1.00 \\
\hline $4.8-$ & 2131 & 253 & $1.12(0.91,1.37)$ & $1.03(0.84,1.28)$ \\
\hline $5.8-$ & 246 & 40 & $1.57(1.08,2.28)$ & $1.32(0.90,1.95)$ \\
\hline $6.8-7.7$ & 45 & 13 & $3.24(1.66,6.31)$ & $2.56(1.27,5.17)$ \\
\hline Total & 4197 & 492 & & \\
\hline Heterogeneity test & & & $\begin{array}{l}\chi^{2}=14.4 \\
3 \mathrm{df}, \mathrm{p}=0.006\end{array}$ & $\begin{array}{l}\chi^{2}=7.77 \\
3 \mathrm{df}, \mathrm{p}=0.05\end{array}$ \\
\hline Trend test & & & $\begin{array}{l}\chi^{2}=10.5 \\
1 \mathrm{df}, \mathrm{p}=0.001\end{array}$ & $\begin{array}{l}\chi^{2}=4.20 \\
1 \mathrm{df}, \mathrm{p}=0.04\end{array}$ \\
\hline
\end{tabular}

^Included in the multivariate model are: age, pre-existing IHD, smoking habit, diastolic blood pressure, total and HDL cholesterol, log triglyceride, and area factor (Caerphilly $v$ Speedwell). had to be in the top half of the distribution of each variable. There were $463(11.0 \%)$ men ( $\mathrm{n}=4197)$ with four metabolic variables and $167(8.8 \%)(n=1896)$ with five. Clusters: the clustering algorithm with four variables gave a metabolic syndrome cluster of 1876 (45\%) of 4197 men, while with five variables there was a cluster of $860(45 \%)$ of 1896 men. Both clusters were characterised by high values for each variable. The composition of the clusters changed only slightly when different initial cluster centres were specified. Log linear model analysis to investigate the pattern of association among variables defining the syndrome was applied using both the tertile and the median cut off points obtained in the first two definitions of the syndrome. When four metabolic variables were used to define the syndrome a contingency table with $2^{4}=16$ cells was obtained. A model specifying independence of the four variables was first fitted. Not surprisingly, in light of the associations shown in table 1 , there was very poor fitting of the data with this model, giving highly significant lack of fit tests and grossly underpredicting the number of men with the syndrome.

A more relevant model specifying no more complicated interrelations among variables than association between each pair was fitted (first two columns of table 2). The data fitted well with this model and enabled prediction of the number of men with the syndrome, which accorded closely with the observed number. When five variables were used to define the syndrome a contingency table with $2^{5}=32$ cells was obtained and findings from the analysis were similar (final two columns of table 2 ).

To assess the relative predictive value and independence of glucose, insulin, and other risk factors multiple logistic regression analyses were performed separately for each cohort and for the combined cohort. Glucose was measured in both cohorts but insulin was measured only in the Caerphilly cohort. The following variables were included as potential confounders: age, smoking habit (never, ex or current), pre-existing IHD, diastolic blood pressure, body mass index, total cholesterol, high density lipoprotein cholesterol, and log triglyceride. Table 3 shows the relative odds of incident IHD by 10 year follow up by increasing fifths of the insulin distribution in the Caerphilly cohort. A significant trend is shown in univariate analysis but adjustment for potential confounder variables shows that fasting serum insulin concentrations no longer make a statistically significant independent contribution to the risk of an IHD event. The exclusion of glucose from the model increased the size of the relative odds marginally but no trend was detectable.

Table 4 shows data for glucose for the combined cohort. Although there is a significant relation between glucose and incident IHD, this effect is confined to the top $20 \%$ of the glucose distribution. Table 5 subdivides the upper three fifths of the glucose distribution by arbitrary units (from $4.8 \mathrm{mmol} / \mathrm{l}$ ). An association between glucose and incident IHD is 
Table 6 Relative odds of incident ischaemic heart disease for three definitions of the metabolic syndrome in non-diabetic men from the combined cohort $(n=4197)$

\begin{tabular}{llll}
\hline & \multicolumn{2}{l}{ Definition of metabolic syndrome (number of men affected) } \\
\cline { 2 - 4 } & $\begin{array}{l}\text { Tertiles } \\
(n=154)\end{array}$ & $\begin{array}{l}\text { Medians } \\
(n=463)\end{array}$ & $\begin{array}{l}\text { Clusters } \\
(n=1876)\end{array}$ \\
\hline $\begin{array}{l}\text { Metabolic syndrome only } \\
\begin{array}{c}\text { Metabolic syndrome adjusted for } \\
\text { age only }\end{array}\end{array}$ & $2.40(1.63,3.53)$ & $1.81(1.40,2.34)$ & $1.90(1.57,2.30)$ \\
$\begin{array}{c}\text { Metabolic syndrome adjusted for } \\
\text { standard risk factors }\end{array}$ & $2.42(1.64,3.57)$ & $1.81(1.40,2.34)$ & $1.92(1.58,2.33)$ \\
$\begin{array}{c}\text { Metabolic syndrome adjusted for } \\
\text { standard and metabolic } \\
\text { syndrome risk factorst }\end{array}$ & $1.87(1.24,2.81)$ & $1.46(1.12,1.92)$ & $1.58(1.29,1.94)$ \\
\hline
\end{tabular}

^ Standard risk factors: age, pre-existing IHD, smoking, total and HDL cholesterol.

†Metabolic syndrome risk factors: triglyceride, glucose, diastolic blood pressure, body mass index.

Table 7 Relative odds of incident ischaemic heart disease for three definitions of the metabolic syndrome in non-diabetic men from the Caerphilly cohort $(n=1896)$

\begin{tabular}{llll}
\hline & \multicolumn{2}{l}{ Definition of metabolic syndrome (number of men affected) } \\
\cline { 2 - 4 } & $\begin{array}{l}\text { Tertiles } \\
(n=50)\end{array}$ & $\begin{array}{l}\text { Medians } \\
(n=167)\end{array}$ & $\begin{array}{l}\text { Clusters } \\
(n=860)\end{array}$ \\
\hline $\begin{array}{l}\text { Metabolic syndrome only } \\
\begin{array}{c}\text { Metabolic syndrome adjusted for } \\
\text { age only }\end{array}\end{array}$ & $2.20(1.11,4.36)$ & $1.60(1.04,2.47)$ & $1.81(1.36,2.41)$ \\
$\begin{array}{c}\text { Metabolic syndrome adjusted for } \\
\text { standard risk factors }\end{array}$ & $2.19(1.10,4.37)$ & $1.62(1.05,2.50)$ & $1.85(1.39,2.46)$ \\
$\begin{array}{c}\text { Metabolic syndrome adjusted for } \\
\text { standard and metabolic } \\
\text { syndrome risk factors }\end{array}$ & $1.81(0.88,3.70)$ & $1.30(0.83,2.04)$ & $1.66(1.22,2.25)$ \\
\hline
\end{tabular}

${ }^{\star}$ Standard risk factors: age, pre-existing IHD, smoking, total and HDL cholesterol.

†Metabolic syndrome risk factors: insulin, triglyceride, glucose, diastolic blood pressure, body mass index. drome (all individuals with a complete set of variables in the upper third or half of the distributions respectively) (table 2) suggested that simple pair wise association of these variables was sufficient to explain these associations; there was no evidence of any complex interrelation among variables.

Cluster analyses were carried out to define metabolic syndrome in a less arbitrary and possibly more physiologically relevant manner. For four and five variable analyses $45 \%$ of men were assigned to a cluster that was characterised by higher mean values for each of the defining variables, these men were regarded as having metabolic syndrome. As in previous analyses, adjustment for individual risk factors removed the excess risk associated with metabolic syndrome defined in this way. These data support the findings of the five year follow up that indicate that a raised serum insulin concentration, a marker for insulin resistance, ${ }^{16}$ is not an independent risk factor for IHD in non-diabetic individuals. A threshold effect for non-fasting insulin concentrations was reported for a specific insulin assay in the British regional heart study. ${ }^{17}$ We also reviewed other studies that investigated insulin as a risk factor for IHD, some of which had a positive relation, ${ }^{18-23}$ while others had no independent relation with subsequent IHD. ${ }^{24-30}$

Blood glucose concentrations, however, show an overall significant association with subsequent IHD but the effect is confined to the top $7 \%$ of the non-diabetic population. The Whitehall study also reported a threshold effect for glucose and subsequent IHD. ${ }^{31}$ The American Diabetes Association and the WHO have recently been considering a redefinition of non-insulin dependent diabetes mellitus. ${ }^{32}$ Our data tend to support the suggestion ${ }^{33}$ that the definition based on fasting blood glucose should be reduced from $7.8 \mathrm{mmol} / 1$ or greater to $7.0 \mathrm{mmol} / 1$ or more, as individuals with fasting glucose concentrations of more than $6.8 \mathrm{mmol} / \mathrm{l}$ are at increased risk of subsequent IHD at $5^{11}$ or 10 year follow up.

Various models of insulin resistance have been proposed, ${ }^{34}{ }^{35}$ and we have shown that a simple model based on the product of fasting insulin and glucose does not carry an increased risk of subsequent IHD in the Caerphilly cohort. $^{36}$

This study has attempted to examine a cluster of variables frequently cited as components of metabolic syndrome. ${ }^{37}$ Our definitions are arbitrary but cover a range of possibilities; using these definitions there is no suggestion of a complex relation among these variables that would justify definition of a separate disease entity. Our definition of metabolic syndrome did not include high density lipoprotein cholesterol but including this factor made no difference to the outcome. There remains, however, the possibility that different components of the syndrome may be more relevant than others to a biological/pathological definition of a syndrome. In other clinically defined syndromes - for example, Paterson-Kelly syndrome (post-cricoid web and dysphagia associated with iron deficiency anaemia) population (table 1) and showed moderately intercorrelation. Log linear modelling of the two arbitrary definitions of metabolic syn- 
data have led to redefinition of components of the syndrome. ${ }^{38}$

Further analyses using different components of a possible syndrome may provide alternative evidence for the existence of such a syndrome in non-diabetic individuals but are beyond the scope of the present study. For example, we did not measure waist:hip ratio, which may provide a measure of abdominal obesity. ${ }^{39}$ This may be more closely associated with metabolic syndrome than an overall measure of body mass index such as that used in this study. Further studies will be required to test these hypotheses.

We thank Dr Tom Trinick for his helpful suggestions and Professor Vincent Marks for the insulin assays.

1 Ferrannini E, Haffner SM, Mitchell BD, et al. Hyperinsulinaemia: the key feature of a cardiovascular and metabolic naemia: the key feature of a cardiovascular

2 Reaven GM. Role of insulin resistance in human disease. Diabetes 1988;37:1595-605.

3 Flier JS. An overview of insulin resistance. In: Moller DE, ed. Insulin resistance. Chichester: Wiley, 1993.

4 Modan M, Halkin H, Fuchs Z, et al. Hyperinsulinemia: a link between hypertension, obesity, and glucose intolerance. $\mathcal{F}$ Clin Invest 1985;75:809-17.

5 DeFronzo RA, Ferrannini E. Insulin resistance: a multifaceted syndrome responsible for NIDDM, obesity, hypertension, dyslipidemia, and atherosclerotic cardiovascular disease. Diabetes Care 1991;14:173-94.

6 Haffner SM, Valdez RZ, Hazuda HP, et al. Prospective analyses of the insulin-resistance syndrome (syndrome $\mathrm{X}$ ). Diabetes 1992;41:716-22.

7 Kaplan NM. The deadly quartet: upper-body obesity, glucose intolerance, hypertriglyceridemia, and hypertension. Arch Intern Med 1989;149:1514-20.

8 Bao W, Srinivasan SR, Berenson GS. Persistent elevation of plasma insulin levels is associated with increased cardiovasplasma insulin levels is associated with increased cardiovas-
cular risk in children and young adults. The Bogalusa heart cular risk in children and young adu
study. Circulation 1996;93:54-9.

9 Reaven GM. Syndrome X: 6 years later. F Intern Med 1994; 236 (suppl 736):13-22.

10 Yarnell JWG, Sweetnam PM, Marks V, et al. Insulin in ischaemic heart disease: are associations mediated by triglyceride levels? The Caerphilly prospective study. Br Hear f 1994;71:293-6.

11 Yarnell JWG, Pickering JE, Elwood PC, et al. Does non-diabetic hyperglycemia predict future IHD? Evidence from the Caerphilly and Speedwell studies. $\mathcal{F}$ Clin Epidemio 1994;47:383-8.

12 Bainton D, Miller NE, Bolton $\mathrm{CH}$, et al. Plasma triglyceride and high density lipoprotein cholesterol as predictors of ischaemic heart disease in British men. Br Heart 7 1992;68 60-6.

13 Bishop YMM, Fienberg SE, Holland PW. Discrete multivariate analysis: theory and practice. Cambridge: MIT Press, ate analy.

14 Rose G, Reid DD, Hamilton PJS, et al. Myocardial ischaemia, risk factors and death from coronary heart disischaemia, risk factors and

15 World Health Organisation Study Group. Diabetes mellitus. WHO Tech Rep Ser 1985:no 727

16 Laakso $M$. How good a marker is insulin level for insulin resistance? Am F Epidemiol 1993;137:959-65.

17 Perry IJ, Wannamethee SG, Whincup PH, et al. Serum insulin and incident coronary heart disease in middle-aged British men. Am f Epidemiol 1996;144:224-34.
18 Ducimetière P, Eschwege E, Papoz L, et al. Relationship of plasma insulin levels to the incidence of myocardial infarction and coronary heart disease in a middle-aged population. Diabetologia 1980;19:205-10.

19 Fontbonne AM, Eschwege EM. Insulin and cardiovascular disease. Paris prospective study. Diabetes Care 1991;14: 461-9.

20 Fontbonne A, Charles MA, Thibult N, et al. Hyperinsulinemia as a predictor of coronary heart disease mortality in a healthy population: the Paris prospective study, 15-year healthy population: the Paris prospective

21 Pyörälä K. Relationship of glucose tolerance and plasma insulin to the incidence of coronary heart disease: results from two population studies in Finland. Diabetes Care 1979;2:131-41.

22 Pyörälä K, Savolainen E, Kaukola S, et al. Plasma insulin as coronary heart disease risk factor: relationship to other risk factors and predictive value during $91 / 2$ year follow-up of the Helsinki policemen study population. Acta Med Scand 1985;701(suppl):38-52.

23 Després J-P, Lamarche B, Mauriège P, et al. Hyperinsulinaemia as an independent risk factor for ischaemic heart disease. N Engl f Med 1996;334:952-7.

24 Welborn TA, Wearne K. Coronary heart disease incidence and cardiovascular mortality in Busselton with reference to glucose and insulin concentrations. Diabetes Care 1979;2: $154-60$

25 Cullen K, Stenhouse NS, Wearne KL, et al. Multiple regression analysis of risk factor for cardiovascular disease and cancer mortality in Busselton, Western Australia-13 year study. Fournal of Chronic Diseases 1983;36:371-7.

26 Hargreaves AD, Logan RL, Elton RA, et al. Glucose tolerance, plasma insulin, HDL-cholesterol and obesity: 12 -year follow-up and development of coronary heart disease in Edinburgh men. Atherosclerosis 1992;94:61-9.

27 Welin L, Eriksson H, Larsson B, et al. Hyperinsulinemia is not a major coronary risk factor in elderly men: the study of men born in 1913. Diabetologia 1992;35:766-70.

28 Orchard TJ, Eichner J, Kuller LH, et al. Insulin as a predictor of coronary heart disease: interaction with apo $\mathrm{E}$ phenotype. A report from MRFIT. Ann Epidemiol 1994;4: $40-9$.

29 Rewers M, Shetterly SM, Baxter J, et al. Insulin and cardiovascular disease in Hispanics and non-Hispanic whites (NHW): the San Luis Valley diabetes study [abstract]. Circulation 1992;85:865.

30 Ferrara A, Barrett-Connor EL, Edelstein SL. Hyperinsulinemia does not increase the risk of fatal cardiovascular disease in elderly men or women without diabetes: the Rancho Bernardo study, 1984-1991. Am f Epidemiol 1994; 140:857-69.

31 Fuller JH, Shipley MJ, Rose G, et al. Mortality from coronary heart disease and stroke in relation to degree of glycaemia: the Whitehall study. BMF 1983;287:867-80

32 De Courten M, Zimmet P. Screening for non-insulindependent diabetes mellitus. Where to draw the line? Diabet Med 1997;14:95-8.

33 Wiener K. Fasting plasma glucose as a screening test for diabetes mellitus. Diabet Med 1997;14:711-12.

34 Rudenski AS, Matthews DR, Levy JC. Understanding "insulin resistance": both glucose resistance and insulin resistance are required to model human diabetes. Metabolism 1991;40:908-17.

35 Duncan MH, Singh BM, Wise PH, et al. A simple measure of insulin resistance. Lancet 1995;346:120-1.

36 Yarnell JWG, Patterson CC, Sweetnam PM. Simple measure of insulin resistance. Lancet 1995;346:1108-9.

37 Williams B. Insulin resistance: the shape of things to come. Lancet 1994;344:521-4.

38 Elwood PC, Jacobs A, Pitman RG, et al. Epidemiology of Patterson-Kelly syndrome. Lancet 1964;ii:716-20.

39 Taskinen M-R. Strategies for the diagnosis of metabolic syndrome. Curr Opin Lipidol 1993;4:434-43. 